\title{
ClearPath: a new method for fast and simple drainage of a perianastomotic abscess
}

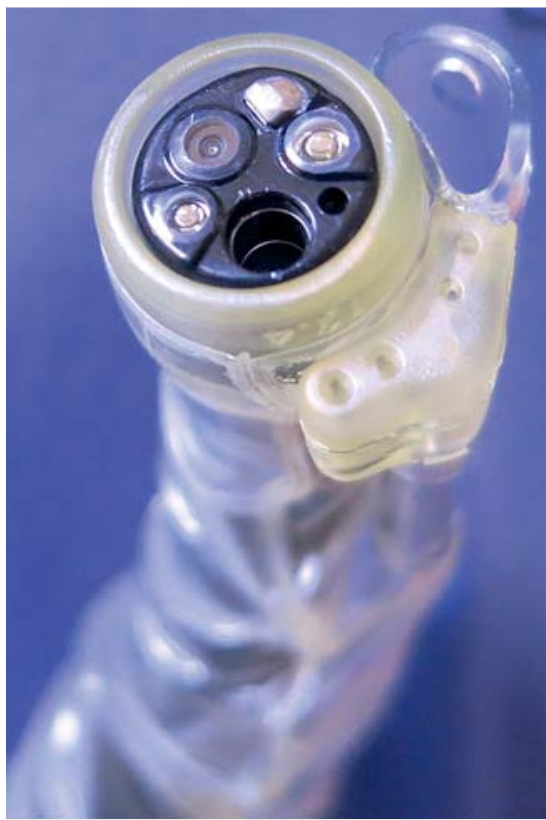

Fig. 1 ClearPath device attached to the tip of the scope.

A-75-year-old man with rectal adenocarcinoma underwent laparoscopic anterior resection with the creation of a protective ileostomy.

Endoscopy done 1 month later to assess the possibility of colonic recanalization revealed a fistula adjacent to the colorectal anastomosis, opening into a $5-\mathrm{cm}$ cavity containing a large amount of feces and necrotic material.

We were unable to drain the cavity with saline irrigation and suction because of continual blocking of the endoscopic suction channel with necrotic material and feces. Because removing this type of waste material with a Roth Net is very time-consuming, we attempted to apply a new technique to clear the cavity and speed up the procedure.

This drainage procedure was carried out with a high definition endoscope (GIFH190; Olympus Medical, Center Valley, Pennsylvania, USA) equipped with a ClearPath cleaning device (Easy-Glide Ltd., Kfar Truman, Israel) ( $\bullet$ Fig. 1), which allowed rapid saline irrigation and efficient suction of the necrotic material and feces in the abscess ( $\bullet$ Fig. 2 , Video 1). Proce-
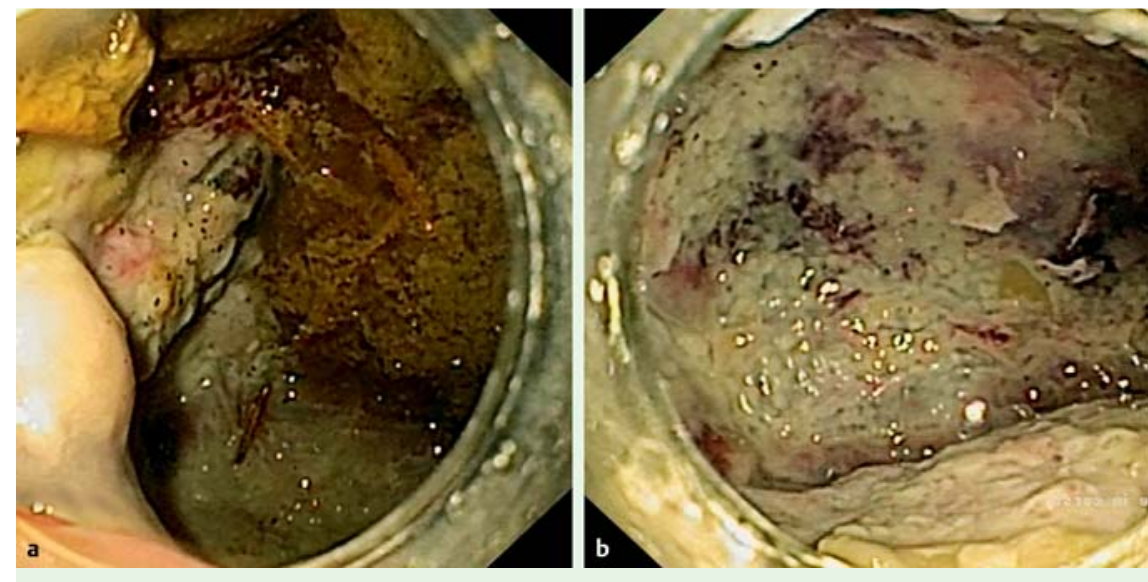

Fig. 2 Use of the cleaning device for saline irrigation and suction of a perianastomotic colorectal abscess: a before drainage; $\mathbf{b}$ after drainage.

dure time was about 1 minute, and there were no adverse events. The clean abscess was then successfully treated with vacuum-assisted transanal therapy until complete closure of the cavity.

The ClearPath device was developed for rapid luminal irrigation and efficient aspiration through its large suction channel, and allows evacuation of fluids, bile, and blood clots during upper gastrointestinal bleeding while keeping the endoscope working channel free for insertion of therapeutic devices [1]. Use of a ClearPath device during underwater endoscopic mucosal resection has also been reported [2]. Endoscopic drainage of feces and necrotic material from an abscess can be difficult and time-consuming, and possibly entail delay for further therapeutic procedures. Though this is a single report that will require confirmation, it describes a fast and simple drainage method, and illustrates a new, useful, and safe application of this ClearPath device.

\section{Video 1}

Drainage of a perianastomotic colorectal abscess using a ClearPath device.

Endoscopy_UCTN_Code_TTT_1AQ_2AG

Competing interests: None

\section{Antonino Granata, Gabriele Curcio, Neville Azzopardi, Luca Barresi, llaria Tarantino, Mario Traina}

Gastroenterology and Endoscopy Unit, Mediterranean Institute for Transplantation and Advanced Specialized Therapies

(ISMETT-UPMC), Palermo, Italy

\section{References}

1 Moshkowitz M, Hirsch Y, Carmel I et al. A novel device for rapid cleaning of poorly prepared colons. Endoscopy 2010; 42: $834-836$

2 Curcio G, Granata A, Azzopardi N et al. ClearPath-assisted underwater endoscopic mucosal resection of a laterally spreading tumor of the colon. Endoscopy 2014; 46: E401 -E41. doi: 10.1055/s-0033-1359127

Bibliography

Dol http://dx.doi.org/

10.1055/s-0034-1377188

Endoscopy 2014; 46: E289

(c) Georg Thieme Verlag KG

Stuttgart · New York

ISSN 0013-726X

\section{Corresponding author}

\section{Antonino Granata, MD}

Gastroenterology and Endoscopy Unit ISMETT/UPMC

Via Tricomi 5

90127 Palermo

Italy

Fax: +39-91-2192400 (specify Endoscopy Service) agranata@ismett.edu 